\section{Age Limit Does Not Replace Serologic Testing for Determination of Immune Status for Measles}

\author{
Ilker Uçkay, MD; Stéphane Hugonnet, MD, MSc; \\ Laurent Kaiser, MD; Hugo Sax, MD; Didier Pittet, MD, MS
}

\begin{abstract}
Adults more than 40 years old are not necessarily immune to measles. A measles outbreak that involved healthcare workers occurred after contact with a 44-year-old patient. Results of a hospitalwide program of mass screening revealed that $117(4.5 \%)$ of 2,600 individuals tested seronegative for measles; $31(26.1 \%)$ of these 117 individuals were more than 40 years old.
\end{abstract}

Infect Control Hosp Epidemiol 2007; 28:1117-1120

Measles is a highly contagious disease and one of the most frequent causes of vaccine-preventable infant mortality worldwide. The disease is usually more severe in adults and in immunocompromised patients. ${ }^{1}$ Because a single dose of vaccine confers only $90 \%$ protection, a second dose is recommended to reduce the rate of primary vaccine failure. In Switzerland, vaccination against measles has been recommended for the general public since 1976 by public health authorities but is not mandatory. Adults born before the mid1960s are believed to be immune, because so many children in that era were exposed to the measles virus and thus developed natural and permanent protection. ${ }^{2}$ Hence, in most developed countries, individuals more than 40 years old are considered to have lifelong immunity.

In January 2005, 4 healthcare workers (HCWs) at the University of Geneva Hospitals were involved in a nosocomial outbreak of measles, together with 35 other individuals identified in the community. The index patient was a 44-year-old man admitted with cough, fever, and macular rash who stayed 16 hours overnight without isolation precautions in a single bay in the emergency department before receiving a diagnosis of measles infection. Two other adults in his workplace became infected, as did the children of a 43 -year-old nurse. None had a past history of receiving 2 doses of vaccine in accordance with national recommendations, ${ }^{2}$ but at least 3 of the adults recalled a past infection during childhood. No severe complications occurred, with the exception of 1 case of secondary bacterial pneumonia. Given the incomplete knowledge of the immunity status of the hospital's HCWs and to contain the possibility of a large nosocomial epidemic, a hospitalwide campaign of mass screening and vaccination against measles was initiated in February 2005.

\section{METHODS}

A comprehensive plan for employee screening and vaccination was rapidly designed. HCWs with patient contact were included on a mandatory basis regardless of age and were given the choice of being vaccinated directly or being tested for measles-specific immunoglobulin G (IgG) antibodies to test their immunity. Employees without patient contact were considered less likely to be at risk for nosocomial measles, and their participation was voluntary. Medical history or past medical reports of measles were not accepted as proof of immunity. Only HCWs with written confirmation of the receipt of 2 doses of vaccine or with a prior positive result of serologic testing were considered protected. Seronegative, nonpregnant HCWs were vaccinated with 1 dose of an attenuated trivalent mumps, measles, and rubella (MMR) vaccine. A second dose of vaccine was given within the following 3 months. Immunocompromised patients with long periods of hospitalization and families of transplant recipients who were followed up at our hospital were included in the screening on a voluntary basis.

The presence of IgG antibodies against measles was assessed by an indirect enzyme-linked immunosorbent assay (Enzygnost Anti-Measles Virus/IgG; Dade Behring Diagnostics) in accordance with the manufacturer's instructions. Testing of cellular immunity was not performed.

\section{RES ULT S}

A total of 3,233 HCWs with direct contact with patients, approximately 150 transplant recipients, and approximately 250 family members of transplant recipients were included in the campaign. A third $(1,100$ of 3,233) of the HCWs preferred to directly receive the MMR vaccine (Figure). Within 6 months, approximately 2,600 adults at our hospital (including approximately $2,300 \mathrm{HCWs}$ ) were tested for the presence of IgG antibodies. Of those tested, $117(4.5 \%)$ were found to be seronegative, and $31(26 \%)$ of those 117 were more than 40 years old. Of those 31,14 were HCWs in good health, and 1 had a smoldering myeloma. The oldest HCW was a 76-year-old female volunteer. Of the 17 seronegative patients more than 40 years old, 8 were immunocompetent and 9 were immunocompromised: 2 bone marrow transplant recipients, 4 renal transplant recipients, 1 cardiac transplant recipient, 1 with cirrhosis, and 1 with acquired immunodeficiency syndrome.

\section{DISCUSSION}

Overall, $4.5 \%$ of all individuals tested by serological analysis at our hospital were shown to be susceptible to measles. Of these, $26 \%$ were born before the introduction of the MMR vaccine. However, one-third of all HCWs opted to be directly vaccinated rather than undergo serologic testing, probably because they considered themselves likely to be nonimmune; thus, the overall prevalence of seronegativity might have been underestimated. During outbreaks of measles, serologic screen- 


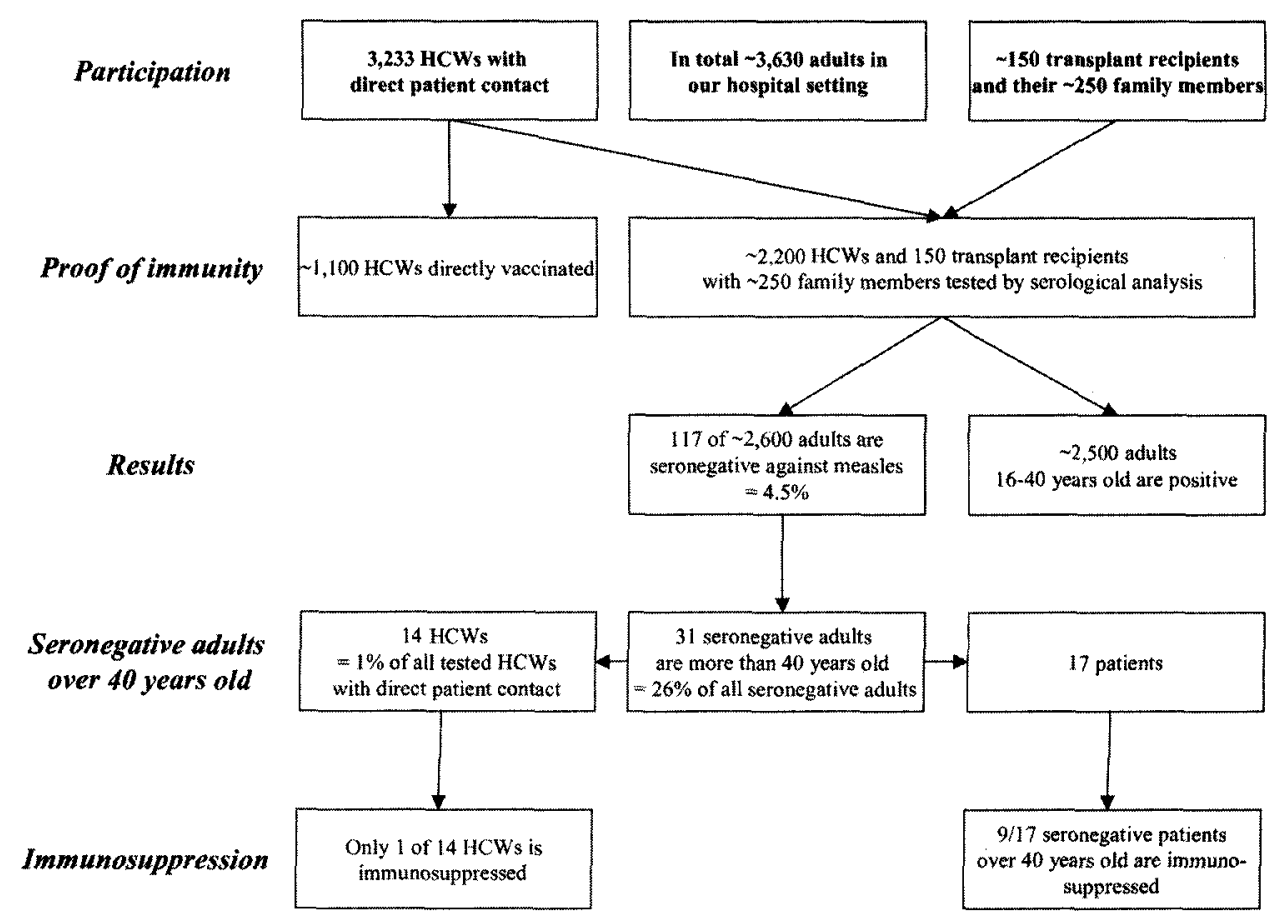

FIGURE. Flowchart of healthcare workers (HCWs) and patients who participated in the mass screening and vaccination campaign against nosocomial measles at the University of Geneva Hospitals, February-July 2005.

ing before vaccination is not recommended, because rapid vaccination is more important to halt the transmission of disease. $^{3}$

Importantly, and contrary to common belief and Swiss national recommendations, ${ }^{2}$ the age limit does not replace serologic immunity testing for measles. Recommendations for adults who do not work in health care vary among countries. In Canada, England, and Wales, individuals more than 35 years old are considered less likely to be susceptible to measles, whereas in France and Germany, vaccination against measles is not recommended for adults more than 25 and 18 years old, respectively. Conversely, in Austria, there is no age limit for measles vaccination, and the US Centers for Disease Control and Prevention recommendations favor 1 vaccine dose for adults more than 50 years old. ${ }^{3}$ Nevertheless, measles cases among very old individuals are rare, and it is probable that

TABLE. Healthcare Workers (HCWs) Who Tested Seronegative for Measles, 1992-2006

\begin{tabular}{|c|c|c|c|c|c|}
\hline Study & Place & $\begin{array}{l}\text { No. of } \\
\text { HCWs }\end{array}$ & $\begin{array}{c}\text { Seronegative } \\
\text { HCWs, \% }\end{array}$ & $\begin{array}{l}\text { Age limit for } \\
\text { testing, years }\end{array}$ & $\begin{array}{c}\text { Nonimmune } \\
\text { HCWs, \% }\end{array}$ \\
\hline Celikbaş et al., ${ }^{9} 2006$ & Ankara, Turkey & 363 & 1.4 & None & NR \\
\hline Hatakeyama et al., ${ }^{10} 2004$ & Tokyo, Japan & 877 & 1.5 & 32 & 0 \\
\hline Ammari et al.," 1993 & Philadelphia, PA & 900 & 1.5 & None & NR \\
\hline Ferson, ${ }^{12} 1994$ & Sydney, Australia & 235 & 1.7 & None & NR \\
\hline Fedeli et al., ${ }^{13} 2002$ & Padua, Italy & 333 & 1.8 & 45 & 0 \\
\hline Ziegler et al., ${ }^{14} 2003$ & Cambridge, United Kingdom & 218 & 3.3 & None & NR \\
\hline Willy et al., ${ }^{15} 1994$ & Bethesda, MD & 2,473 & 4.0 & 38 & 8.6 \\
\hline Steingart et al., ${ }^{1} 1999$ & United States (various hospitals) & 7,535 & 4.0 & None & NR \\
\hline Kim et al., ${ }^{16} 1992$ & Hawaii & 2,075 & 4.9 & 40 & 7.9 \\
\hline Asari et al., ${ }^{17} 2003$ & Osaka, Japan & 271 & 7.4 & 31 & 12.5 \\
\hline Seo et al., ${ }^{18} 2002$ & New York City, NY & 1,349 & 9.0 & 39 & 3.1 \\
\hline Wright and Carlquist, ${ }^{19} 1994$ & Utah & 5,825 & 10.3 & 35 & 8.1 \\
\hline Almuneef et al., ${ }^{20} 2006$ & Riyadh, Saudi Arabia. & 4,006 & 13.0 & None & NR \\
\hline
\end{tabular}

NOTE. NR, not reported.

"Above age limit for testing. 
the upper age limit for the risk of measles is not indefinitely high. On the basis of our experience during the nosocomial outbreak described here that involved at least 2 immunocompetent adults more than 40 years old, we believe that the risk is real for this age group, among both patients and HCWs. It is known that transplant recipients can lose seropositivity for measles after undergoing transplantation, ${ }^{4}$ antibodies can wane over time even in healthy individuals, ${ }^{5}$ and exposure to wild-type virus is less common today, which potentially results in an inferior boosting of immunity, similar to what has been discussed for varicella zoster virus in a highly vaccinated population. The small number of seronegative transplant recipients does not alter the key message of our report. Immunity to measles is conferred by the interplay of humoral and cellular responses. Serum antibodies may only partly correlate with protection against measles infection or disease, but the relative contribution of cellular immunity to protection in response to vaccination remains unknown. ${ }^{6}$ In accordance with common practice and recommendations, ${ }^{3}$ we did not measure cellular immunity in our campaign.

In Switzerland, despite reimbursement by health insurance, general vaccination coverage is insufficient, mostly because of alternative beliefs, particularly among nurses. ${ }^{7}$ Coverage against measles falls short of the amount needed to prevent the regular occurrence of outbreaks, which requires a herd immunity of more than $95 \% .{ }^{8}$ Internationally, the prevalence of susceptibility to measles among HCWs ranges from $1.4 \%$ to $13 \%$ (Table), and only a few reports provide details of the age groups involved among nonimmune HCWs. Our results are in agreement with those from other countries. The vaccination status of HCWs is considered a parameter for patient safety in healthcare institutions. ${ }^{21}$ HCWs have a nearly 19fold higher risk of infection with measles compared with that of the general population. ${ }^{1}$ Of note, $27 \%$ of all measles cases in the United States during 1993-1995 involved individuals more than 20 years old, with $13.9 \%$ occurring in a healthcare setting.

A hospital is responsible for the health of its employees and patients. Given the high contagiousness of the measles virus, the severity of the disease in adults, and the safety and cost-effectiveness of the vaccine, all medical institutions should ensure that all HCWs are immunized against measles. ${ }^{3}$ Importantly, age should no longer be considered in the decision of whether to vaccinate. ${ }^{3,22}$ Instead, proof of immunity by direct vaccination or serological analysis should be mandatory, as is now the case for every new employee at our hospital. However, compliance with these recommendations is poor ${ }^{1}$ and clearly must be reinforced in hospitals and in the general population.

\section{ACKNOWLEDGMENTS}

We are indebted to Rosemary Sudan for providing editorial assistance and to Dr. Werner Wunderli (Laboratory of Virology) and Prof. Claire-Anne Siegrist (Department of Pediatrics and Centre for Vaccinology and Neonatal
Immunology) for their scientific contribution. We also thank Claude Ginet (Infection Control Program), Dr. Nadia Bessire (Employee Health Service), Marie-Hélène Loetscher (Employee Health Service), Dr. Olivier Rutschmann (Department of Internal Medicine), Dr. Alain Gervaix (Department of Pediatrics), Dr. Bernard Vermeulen (Accident and Emergency Unit), Pierre Brennenstuhl (General Directorate), Dr. Philippe Sudre (Geneva Cantonal Health Directorate), and Dr. Carmem Aramburu (Geneva Cantonal Health Directorate).

Potential conflicts of interest. All authors report no conflicts of interest relevant to this article.

From the Infection Control Program (I.U., S.H., H.S., D.P.) and the Laboratory of Virology (L.K.), University of Geneva Hospitals, Geneva, Switzerland.

Address reprint requests to Didier Pittet, MD, MS, Director, Infection Control Program, University of Geneva Hospitals, 24 Rue Micheli-du-Crest, 1211 Geneva 14, Switzerland (didier.pittet@hcuge.ch).

Received January 23, 2007; accepted March 22, 2007; electronically published July 3, 2007.

(C) 2007 by The Society for Healthcare Epidemiology of America. All rights reserved. 0899-823X/2007/2809-0020\$15.00. DOI: $10.1086 / 519928$

\section{REFERENCES}

1. Steingart KR, Thomas AR, Dykewicz CA, Redd SC. Transmission of measles virus in healthcare settings during a community-wide outbreak. Infect Control Hosp Epidemiol 1999; 20:115-119.

2. Swiss Federal Office of Public Health. Eidgenössische Komission für Impffragen (EKIF). Schweizerischer Impfplan 2006. Richtinien und Empfehlungen. Bern: Swiss Federal Office of Public Health; 2006.

3. Immunization of healthcare workers: recommendations of the Advisory Committee on Immunization Practices (ACIP) and the Hospital Infection Control Practices Advisory Committee (HICPAC). MMWR Recomm Rep 1997; 46(RR-18):1-42.

4. Ljungman $P$, Aschan J, Barkholt $L$, et al. Measles immunity after allogeneic stem cell transplantation: influence of donor type, graft type, intensity of conditioning, and graft-versus host disease. Bone Marrow Transplant 2004; 34:589-593.

5. Kremer JR, Schneider F, Muller CP. Waning antibodies in measles and rubella vaccines-a longitudinal study. Vaccine 2006; 24:2594-2601.

6. Dhiman N, Ovsyannikova IG, Ryan JE, et al. Correlations among measles virus-specific antibody, lymphoproliferation and Th1/Th2 cytokine responses following measles-mumps-rubella-II (MMR-II) vaccination. Clin Exp Immunol 2005; 142:498-504.

7. Masserey E, Bouvier $P$, Brenner $E$, et al. Vaccinal coverage and its determinants in preschool children in Vaud canton in 1996. Rev Med Suisse Romande 1998; 118:309-315.

8. Anderson RM, May RM. Immunisation and herd immunity. Lancet 1990; 335:641-645.

9. Çelikbaş A, Ergonul O, Aksaray S, et al. Measles, rubella, mumps, and varicella seroprevalence among health care workers in Turkey: is prevaccination screening cost-effective? Am J Infect Control 2006; 34:583-587.

10. Hatakeyama $S$, Moriya $K$, Itoyama $S$, et al. Prevalence of measles, rubella, mumps, and varicella antibodies among healthcare workers in Japan. Infect Control Hosp Epidemiol 2004; 25:591-594.

11. Ammari LK, Bell LM, Hodinka RL. Secondary measles vaccine failure in healthcare workers exposed to infected patients. Infect Control Hosp Epidemiol 1993; 14:81-86.

12. Ferson MJ. Control of infections in child care. Med J Aust 1994; 161: 615-618.

13. Fedeli U, Zanetti C, Saia B. Susceptibility of healthcare workers to measles, mumps, rubella and varicella. $J$ Hosp Infect 2002; 51:133-135.

14. Ziegler E, Roth C, Wreghitt T. Prevalence of measles susceptibility among health care workers in a UK hospital: does the UK need to introduce a 
measles policy for its health care workers? Occup Med (Lond) 2003; 53: 398-402.

15. Willy ME, Koziol DE, Fleisher T, et al. Measles immunity in a population of healthcare workers. Infect Control Hosp Epidemiol 1994; 15:12-17.

16. Kim M, LaPointe J, Liu FJ. Epidemiology of measles immunity in a population of healthcare workers. Infect Control Hosp Epidemiol 1992; 13:399-402.

17. Asari S, Deguchi M, Tahara K, et al. Seroprevalence survey of measles, rubella, varicella, and mumps antibodies in health care workers and evaluation of a vaccination program in a tertiary care hospital in Japan. Am J Infect Control 2003; 31:157-162.

18. Seo SK, Malak SF, Lim S, Eagan J, Sepkowitz KA. Prevalence of measles antibody among young adult healthcare workers in a cancer hospital: 1980s versus 1998-1999. Infect Control Hosp Epidemiol 2002; 23:276-278.
19. Wright LJ, Carlquist JF. Measles immunity in employees of a multihospital healthcare provider. Infect Control Hosp Epidemiol 1994; 15:8-11.

20. Almuneef MA, Memish ZA, Balkhy HH, Otaibi B, Helmi M. Seroprevalence survey of varicella, measles, rubella, and hepatitis $A$ and $B$ viruses in a multinational healthcare workforce in Saudi Arabia. Infect Control Hosp Epidemiol 2006; 27:1178-1183.

21. Krause PJ, Gross PA, Barrett TL, et al. Quality standard for assurance of measles immunity among health care workers. Infectious Diseases Society of America. Clin Infect Dis 1994; 18:431-436.

22. Mühlemann K, Aebi C, Zysset F, Francioli P. Vaccination du personnel hospitalier contre la rougeole, les oreillons et la rubéole. Swiss-NOSO Bulletin 2001; 8:13-15. Available at: http://www.swiss-noso.ch. Accessed June 27, 2007. 